\title{
SICK EUTHYROID SYNDROME IN CHRONIC KIDNEY DISEASE
}

Jigar Haria1, Manish Lunia²

\section{HOW TO CITE THIS ARTICLE:}

Jigar Haria, Manish Lunia. "Sick euthyroid syndrome in chronic kidney disease". Journal of Evolution of Medical and Dental Sciences 2013; Vol. 2, Issue 43, October 28; Page: 8267-8273.

ABSTRACT: BACKGROUND: Sick euthyroid syndrome is an undermined entity seen in many chronic illness. CKD is one of the forerunners in terms of magnitude in the list of chronic illnesses. Also there is evidence of abnormal thyroid metabolism at several levels in uremia. Hence the need to evaluate thyroid function in CKD patients exists, as revealed by recent studies. AIMS: To study thyroid function test in patients of chronic renal failure. Also, to study the correlation between thyroid function test and severity of renal failure, defined by creatinine clearance. MATERIALS \& METHODS: In a cross sectional observational case control study, 50 patients of chronic renal failure either on conservative management or on maintenance haemodialysis and 50 normal healthy subjects as control were en rolled. Creatinine clearance was calculated by Cockcroft - Gault Equation. Thyroid function tests were done by C.L.I.A (Chemiluminescence Immunoassay). RESULTS: Of the 50 patients (M:F - 58:42\%), with a mean age $40.58 \pm 12.65$ years, 28 (56\%) were on conservative management, 22 (44\%) were on hemodialysis for a minimum period of three months. All patients were clinically euthyroid. Thyroid function tests were normal (all parameters within normal range) in 13 (26\%) patients. However 37 (74\%) out of 50 patients of CKD had deranged thyroid function test (sick euthyroid syndrome). Mean Total T3 in patients of CKD and controls were $71.52 \pm$ $27.88 \mathrm{ng} / \mathrm{dl}$ and $95.34 \pm 16.31 \mathrm{ng} / \mathrm{dl}$ respectively $(\mathrm{p}<0.005)$. Mean Free T3 in patients of CKD and controls were $2.19 \pm 0.70 \mathrm{pg} / \mathrm{ml}$ and $3.23 \pm 0.79 \mathrm{pg} / \mathrm{ml}$ respectively $(\mathrm{p}<0.005)$. Mean Total T4 in patients of CKD and controls were $6.03 \pm 1.60 \mu \mathrm{g} / \mathrm{dl}$ and $6.88 \pm 1.06 \mu \mathrm{g} / \mathrm{dl}$ respectively $(\mathrm{p}<0.005)$. Mean Free T4 in patients of CKD and controls were $1.18 \pm 0.55 \mathrm{ng} / \mathrm{ml}$ and $1.29 \pm 0.24 \mathrm{ng} / \mathrm{dl}$ respectively (no statistically significant difference). Mean TSH in patients of CKD and controls were $2.90 \pm 1.39$ vs. $2.81 \pm 0.99 \mu \mathrm{IU} / \mathrm{ml}$ respectively (no statistically significant difference). On applying correlation statistics, no statistically significant correlation was found between creatinine clearance and thyroid function test (r NS). Similarly, no statistically significant correlation was found between blood urea, serum creatinine, and various thyroid function test. CONCLUSION: Our study indicated low Total T3, Free T3 and Total T4 levels in 74\% CKD patients as compared to controls. However, Free T4 and TSH level were found to be comparable to controls. Deranged thyroid function in patients of CKD could be due to sick euthyroid syndrome. No statistically significant correlation was found between thyroid function test and severity of renal failure.

KEYWORDS: Thyroid, Sick euthyroid Syndrome, Chronic Kidney Disease

INTRODUCTION: Chronic kidney disease is fast emerging as an important chronic illness of great morbidity and mortality. In past two decades, with the advent of renal replacement therapy like hemodialysis and renal transplantation, it has been possible to increase the longevity of CKD patients. With longevity arise the problems of various organs involvements and insight in their genesis. Endocrinopathies is one of them and one of the most debated topics in renal disease. Can cold intolerance, fatigue, anorexia be attributed to thyroid dysfunction or they are just part of spectrum of term "Uremia"; as kidney plays a significant role in thyroid hormone metabolism by 
conversion of T4 to T3 and excretion of inorganic iodides. Do the toxic substances of uremia affect thyroid gland? Does duration of uremia affect the dysfunction? Is thyroid dysfunction related to disease severity? Answer to all these question hold keys to newer diagnostic strategies, better planning and management with the aim to reduce morbidity and mortal ity in these patients. Various authors like Ramirez G(1976) ${ }^{1}$, Lim VS(1977)2 , Kaptein EM(1983)33, Mehta HJ(1991)4, Kayima JK(1992) ${ }^{5}$, Reinhardt W(1997)6, Zoccali C(2005)7, Honda $\mathrm{H}(2006)^{8}$ have tried to solve this puzzle from various angles and have postulated abnormalities at various level in hypothalamo-pituitarythyroid axis, aberrant binding of thyroid hormone with serum binding protein and peripheral metabolism of thyroid hormone and iodides. They have also studied the effect of various modes of dialysis on thyroid functions. Recent studies have found relationship between free T3 and inflammation markers (IL-6 and C-reactive protein) and markers of endothelial activation (intercellular adhesion molecule-1 [ICAM-1] and vascular cellular adhesion molecule-1 [VCAM-1] . Low circulating free T3 is frequently observed in inflammatory illnesses, and the same association exists in patients with CKD and in ESRD10.

MATERIALS AND METHODS: This cross sectional observational case control study, was conducted at Teerthanker Mahaveer Medical College, Moradabad, UP with the approval of the ethical committee during a one year period from May 2012 to April 2013. 50 patients of chronic renal failure and 50 normal healthy subjects as control. Patients were either on conservative management (group 1) or on haemodialysis (group 2) for minimum 3 months duration.

Inclusion criteria: Patients who were clinically diagnosed as chronic renal failure with derangements in kidney function test (blood urea, serum creatinine, creatinine clearance) and were found to have small shrunken kidney with increased echogenicity and loss of corticomedullary differentiation on ultrasonography were included in the study.

Exclusion criteria: Acute renal failure, Known thyroid disease, Diabetes mellitus, Acquired immune deficiency syndrome, Pregnancy, patients on Drugs: antithyroid drugs, anti epileptics, propranolol, amiodarone, steroids, oral contraceptive pills, lithium.

50 patients, according to inclusion and exclusion criteria and 50 normal subjects were included in the study. All these patients were subjected to detailed history (symptoms, past illnesses, treatments - Oliguria/ anuria, Anorexia, Vomiting/nausea, Constipation/ diarrhea, Wt gain/loss, oedema, Fatigue/weakness, Myalgia, Breathlessness, Tingling / numbness, Cold intolerance, Bleeding tendency, Neuro-psychiatric symptoms, Menstrual complaints) and a thorough general and systemic exam. All routine investigations along with Renal functions, Creatinine clearance by Cockroft-Gault method, Renal ultrasound and Thyroid function tests (Total \& free T3, Total \& free T4, TSH) was done. Thyroid function tests were done by C.L.I.A (Chemiluminescence Immunoassay). The data thus collected was analyzed using statistical software SPSS.v15 using student " $\mathrm{t}$ " test, one way analysis of variance (ANOVA), percentage, proportion, and correlation statistics.

RESULTS: Out of 50 patients of CKD, 29 (58\%) were male and 21 (42\%) were female. Similarly, out of 50 controls, $29(58 \%)$ were male and $21(42 \%)$ were female. The mean age of patients and control were $40.58 \pm 12.65$ years and $41.76 \pm 13.67$ years respectively. Age range of study patients was 19 years to 64 years. Maximum (52\%) patients were in age group 31 - 50 years. Mean duration of symptoms was $8.77 \pm 4.56$ months. Of the 50 patients of CKD, $30(60 \%)$ presented with oliguria, 10 
(20\%) presented with anuria. Signs of fluid overload like oedema, rales were seen in 15 (30\%) patients. Generalized weakness and fatigue was seen in majority i.e 47 (94\%) patients. Asterixis were seen in $35(70 \%)$, pericardial rub was seen in $10(20 \%)$ patients. 30 patients $(60 \%)$ also had persistent vomiting as presenting complaint. Out of 50 patients, 28 (56\%) were in group 1 (conservative management), 22 (44\%) were in group 2 (hemodialysis). Mean blood urea in patients and controls were $166.78 \pm 77.21 \mathrm{mg} \%$ and $18.19 \pm 4.22 \mathrm{mg} \%$ respectively $(\mathrm{p}<0.005)$. Mean serum creatinine in patients and controls were $9.57 \pm 5.51 \mathrm{mg} \%$ and $0.67 \pm 0.16 \mathrm{mg} \%$ respectively $(\mathrm{p}<$ 0.005). All patients were clinically euthyroid, none having any symptoms or signs of either hypothyroidism or hyperthyroidism. Thyroid function tests were normal (all parameter within normal range) in 13 (26\%) patients. However 37 (74\%) out of 50 patients of CKD had deranged thyroid function test. The mean Total T3 in patients of CKD and controls were $71.52 \pm 27.88$ vs. $95.34 \pm 16.31 \mathrm{ng} / \mathrm{dl}$ respectively $(\mathrm{p}<0.005) .27$ (54\%) patients of CKD had Total T3 value less than normal range $(<60 \mathrm{ng} / \mathrm{dl})$ whereas none of the control had Total T3 value less than normal range. Mean Total T4 in patients of CKD and controls were $6.03 \pm 1.60$ vs. $6.88 \pm 1.06 \mu \mathrm{g} / \mathrm{dl}$ respectively (p $<0.005) .13(26 \%)$ of the CKD patients as compared to none in the control group had serum T 4 concentration below normal range. Mean Free T3 in patients of CKD and controls were $2.19 \pm 0.70$ vs. $3.23 \pm 0.79 \mathrm{pg} / \mathrm{ml}$ respectively $(\mathrm{p}<0.005) .10(20 \%)$ of the CKD patients as compared to none in the control group had serum Free T3 concentration below normal range. The mean Free T4 in patients of CKD and controls were $1.18 \pm 0.55$ vs. $1.29 \pm 0.24 \mathrm{ng} / \mathrm{dl}$ respectively (p NS, no statistically significant difference). Mean TSH in patients of CKD and controls were $2.90 \pm 1.39$ vs. $2.81 \pm$ $0.99 \mu \mathrm{IU} / \mathrm{ml}$ respectively (p NS, no statistically significant difference). Thus, there was statistically significant decrease in Total T3, Total T4 and Free T3 in patients of CKD as compared to controls. However Free T4 and TSH in two groups were comparable.

\begin{tabular}{|c|c|c|c|c|}
\hline Parameter & $\begin{array}{c}\text { Control } \\
(\mathrm{n}=50)\end{array}$ & $\begin{array}{c}\text { Patients } \\
(\mathrm{n}=50)\end{array}$ & $\begin{array}{c}\text { Group 1 } \\
(\mathrm{n}=28)\end{array}$ & $\begin{array}{c}\text { Group 2 } \\
(\mathrm{n}=22)\end{array}$ \\
\hline $\begin{array}{c}\mathrm{TT} 3 \\
(\mathrm{~N} 60-200 \mathrm{ng} / \mathrm{dl})\end{array}$ & $95.34 \pm 16.31$ & $71.52 \pm 27.88$ & $74.05 \pm 24.45$ & $62.41+17.85$ \\
\hline $\begin{array}{c}\mathrm{TT} 4 \\
(\mathrm{~N} 4.5-2 \mu \mathrm{g} / \mathrm{dl})\end{array}$ & $6.88 \pm 1.06$ & $6.03 \pm 1.60$ & $6.09 \pm 1.76$ & $5.98 \pm 1.48$ \\
\hline $\begin{array}{c}\mathrm{FT} 3 \\
(\mathrm{~N} 1.7-4.2 \mathrm{pg} / \mathrm{ml})\end{array}$ & $3.23 \pm 0.79$ & $2.19 \pm 0.70$ & $2.19 \pm 0.86$ & $2.70 \pm 0.56$ \\
\hline $\begin{array}{c}\mathrm{FT} 4 \\
(\mathrm{~N} 0.7-1.8 \mathrm{ng} / \mathrm{dl})\end{array}$ & $1.29 \pm 0.24$ & $1.18 \pm 0.55$ & $1.21 \pm 0.71$ & $1.25 \pm 0.20$ \\
\hline $\begin{array}{c}\mathrm{TSH} \\
(\mathrm{N} 0.3-5.5 \mu \mathrm{IU} / \mathrm{ml})\end{array}$ & $2.81 \pm 0.99$ & $2.90 \pm 1.39$ & $2.89 \pm 1.58$ & $3.32 \pm 0.13$ \\
\hline \multicolumn{2}{|r|}{$\mathrm{TABLE} 1:$ Thyroid function test in controls and in patients } \\
\hline
\end{tabular}


ORIGINAL ARTICLE

\begin{tabular}{|c|c|c|c|c|}
\hline \multirow{2}{*}{ Parameter } & \multirow{2}{*}{ Controls $(n=50)$} & \multicolumn{3}{|c|}{ Creatinine clearance (ml/minute) } \\
\hline & & $<8 \mathrm{ml}(\mathrm{n}=16)$ & $8-15 m l(n=23)$ & $>15 \mathrm{ml}(\mathrm{n}=11)$ \\
\hline $\begin{array}{c}\text { TT3 } \\
\text { (N 60-200ng/dl) }\end{array}$ & $95.34 \pm 16.31$ & $78.33 \pm 26.14$ & $70.61 \pm 20.55$ & $76.15 \pm 30.32$ \\
\hline $\begin{array}{c}\mathrm{TT} 4 \\
(\mathrm{~N} 4.5-2 \mu \mathrm{g} / \mathrm{dl})\end{array}$ & $6.88 \pm 1.06$ & $4.77 \pm 1.57$ & $6.72 \pm 1.56$ & $6.06 \pm 1.82$ \\
\hline $\begin{array}{c}\text { FT3 } \\
(\mathrm{N} 1.7-4.2 \mathrm{pg} / \mathrm{ml})\end{array}$ & $3.23 \pm 0.79$ & $1.73 \pm 0.80$ & $2.29 \pm 0.67$ & $2.37 \pm 1.04$ \\
\hline $\begin{array}{c}\text { FT4 } \\
(\mathrm{N} 0.7-1.8 \mathrm{ng} / \mathrm{dl})\end{array}$ & $1.29 \pm 0.24$ & $0.96 \pm 0.44$ & $1.58 \pm 0.82$ & $0.85 \pm 0.40$ \\
\hline $\begin{array}{c}\text { TSH } \\
(\mathrm{N} 0.35 .5 \mu \mathrm{IU} / \mathrm{ml})\end{array}$ & $2.81 \pm 0.99$ & $2.22 \pm 1.68$ & $2.48 \pm 1.16$ & $3.93 \pm 1.69$ \\
\hline
\end{tabular}

There was no statistically significant difference in Total T3, Total T4, Free T3 and Free T4 values between the groups as per creatinine clearance ( $p$ NS). However there was a direct correlation between TSH and creatinine clearance, value of TSH decreased as creatinine clearance decreased $(\mathrm{P}<0.05)$. On applying correlation statistics, no statistically significant correlation was found between blood urea, serum creatinine, creatinine clearance and thyroid function tests i.e.; Total T3, Total T4, Free T3, Free T4 and TSH (r - NS).

DISCUSSION: Any severe illness can cause abnormalities of circulating TSH or thyroid hormone levels in the absence of underlying thyroid disease, making these measurements potentially misleading. The major cause of these hormonal changes is the release of cytokines. The most common hormone pattern in sick euthyroid syndrome is a decrease in total and unbound $\mathrm{T}_{3}$ levels (low $\mathrm{T}_{3}$ syndrome) with normal levels of $\mathrm{T} 4$ and $\mathrm{TSH}$. The magnitude of the fall in $\mathrm{T}_{3}$ may correlate with the severity of the illness. $\mathrm{T}_{4}$ conversion to $\mathrm{T}_{3}$ via peripheral deiodination is impaired. Fluctuation in TSH levels also creates challenges in the interpretation of thyroid function in sick patients. The underlying mechanism may be mediated by cytokines including IL-12 and IL-1811. As kidney plays a significant role in thyroid hormone metabolism by conversion of T4 to T3 and excretion of inorganic iodides, thyroid function has been evaluated by many investigators in patients with CKD. Levels of Total T3 and Free T3 suffer reduction in CKD, which is thought to be due to impairment in deiodination of T4, secondarily to decrease activity of de-iodinase enzymes. As kidneys are important organ of excretion of iodide, accumulation of inorganic iodides may lead to decreased uptake by thyroid glands due to Wolf-Chaikoff effect and may cause hypothyroidism ${ }^{12}$. A multitude of defects at all levels of hypothalamic - pituitary - thyroid - peripheral axis does seem to exist in uremia ${ }^{13}$, which include impaired release of TSH in response to TRH (thyrotrophic releasing hormone), impaired thyroid hormone secretion in response to TSH. Cytokines particularly IL-1, IL-6, TNF $-\alpha$ and interferon $\beta$ are thought to affect the hypothalamus, pituitary and other tissues, inhibiting production of TRH, TSH, thyroglobulin, T3, TBG and also thought to decrease the activity of type I deiodinase and to decrease the binding capacity of T3 nuclear receptor ${ }^{8}$. In our study, 37 (74\%) out of 50 patients of CKD had deranged thyroid function test (sick euthyroid syndrome). Total T4, Total T3, Free T3 values were found lower in CKD patients as compare to controls. However, Free T4 and TSH values in patients and controls were comparable. Also, no statistically significant correlation was found between serum Total T3, Total T4, Free T3, Free T4 and TSH values and 
creatinine clearance (r NS) i.e., there was no statistically significant correlation between thyroid function test and severity of renal failure. "Low T3 syndrome" was the common type in our study. 27 (54\%) patients of CKD had Total T3 value less than normal range $(<60 \mathrm{ng} / \mathrm{dl})$ and $10(20 \%)$ patients had low free T3 levels. Mean TSH in these patients of were comparable to controls suggesting an impaired feedback mechanism and/or abnormality TSH secretion.Total T4 concentration was found to be low or low normal. 13 (26\%) of the CKD patients as compared to none in the control group had serum T4 concentration below normal range. However, Free T4 was within normal limit. This could be attributed to lowering of thyroxin binding globulin concentration as well as inhibitors of thyroid hormone binding to thyroid binding proteins ${ }^{12,13}$. These binding inhibitors are associated with non-esterified fatty acid (NEFA) fraction in the serum ${ }^{14,15}$. rT3 level could not be measured in our study.

CONCLUSION: Deranged thyroid function in patients of CKD could be due to sick euthyroid syndrome. Most common hormonal pattern was low total T3, low total T4 and low free T3 in decreasing frequency.

\section{REFERENCES:}

1. Ramirez G, O'Neill W J, Jubiz W, Bloomer HA. Thyroid dysfunction in uremia: evidence for thyroid and hypophyseal abnormalities, Annals of Internal Medicine 1976 (84): 672-76.

2. Lim VS, Fang VS, Katz AI, Refetoff S. Thyroid dysfunction in chronic renal failure: A study of the pituitary-thyroid axis and peripheral turnover kinetics of thyroxine and triiodothyronine. J Clin Invest. 1977 Sep; 60(3):522-34.

3. Kaptein EM, Feinstein EI, Nicoloff JT, Massry SG. Alterations of serum reverse triiodothyronine and thyroxine kinetics in chronic renal failure: role of nutritional status, chronic illness, uremia, and hemodialysis. Kidney IntSuppl 1983 Dec; 16:180-86

4. Mehta HJ, Joseph LJ, Desai KB, Mehta MN, Samuel AM, Almeida AF, Acharya VN. Total and free thyroid hormone levels in chronic renal failure, J post grad med 1991; 37(1): 79-83

5. Kayima JK, Otieno LS, Gitau W, Mwai S. Thyroid hormone profiles in patients with chronic renal failure on conservative management and regular haemodialysis. East Afr Med J 1992 Jun; 69(6):333-36.

6. Reinhardt W, Misch C, Jockenhövel F, Wu SY, Chopra I, Philipp T, Reinwein D, Eigler FW, Mann K. Triiodothyronine (T3) reflects renal graft function after renal transplantation. ClinEndocrinol (Oxf) 1997 May; 46(5):563-69.

7. Zoccali C, Tripepi G, Cutrupi S, Pizzini P, Mallamaci F. Low triiodothyronine: a new facet of inflammation in end-stage renal disease. J Am SocNephrol 2005 Sep; 16(9):2789-95.

8. Honda H, Qureshi AR, Heimbürger O, Barany P, Wang K, Pecoits-Filho R, Stenvinkel P, Lindholm B. Serum albumin, C-reactive protein, interleukin 6, and fetuin a as predictors of malnutrition, cardiovascular disease, and mortality in patients with ESRD. Am J Kidney Dis 2006 Jan; 47(1):139-48.

9. Bartalena L, Brogioni S, Grasso L, Velluzzi F, Martino E. Relationship of the increased serum interleukin-6 concentration to changes of thyroid function in nonthyroidal illness. J Endocrinol Invest 1994 Apr; 17(4):269-74.

10. Zoccali C, Tripepi G, Cutrupi S, Pizzini P, Mallamaci F. Low triiodothyronine: a new facet of inflammation in end-stage renal disease. J Am SocNephrol 2005 Sep; 16(9):2789-95. 
11. J Larry Jameson, Anthony P W; Harrisons: Principles of Internal Medicine, $18^{\text {th }}$ Ed, chap 341, pg 2929.

12. KapteinEM.Thyroid hormone metabolism and thyroid diseases in chronic renal failure. Endocr Rev 1996 Feb; 17(1):45-63.

13. James L, William E. Pathophysiology of anemia. In "The Kidney". 7th edition. W B Saunders; 2003, pp 2150-52.

14. Serhat A. Euthyroid Sick Syndrome, www.emedicine.com

15. Inder J. Chopra. Euthyroid sick syndrome: Is it a misnomer? The journal of clinical endocrinology and metabolism 1997; 82:329-34.
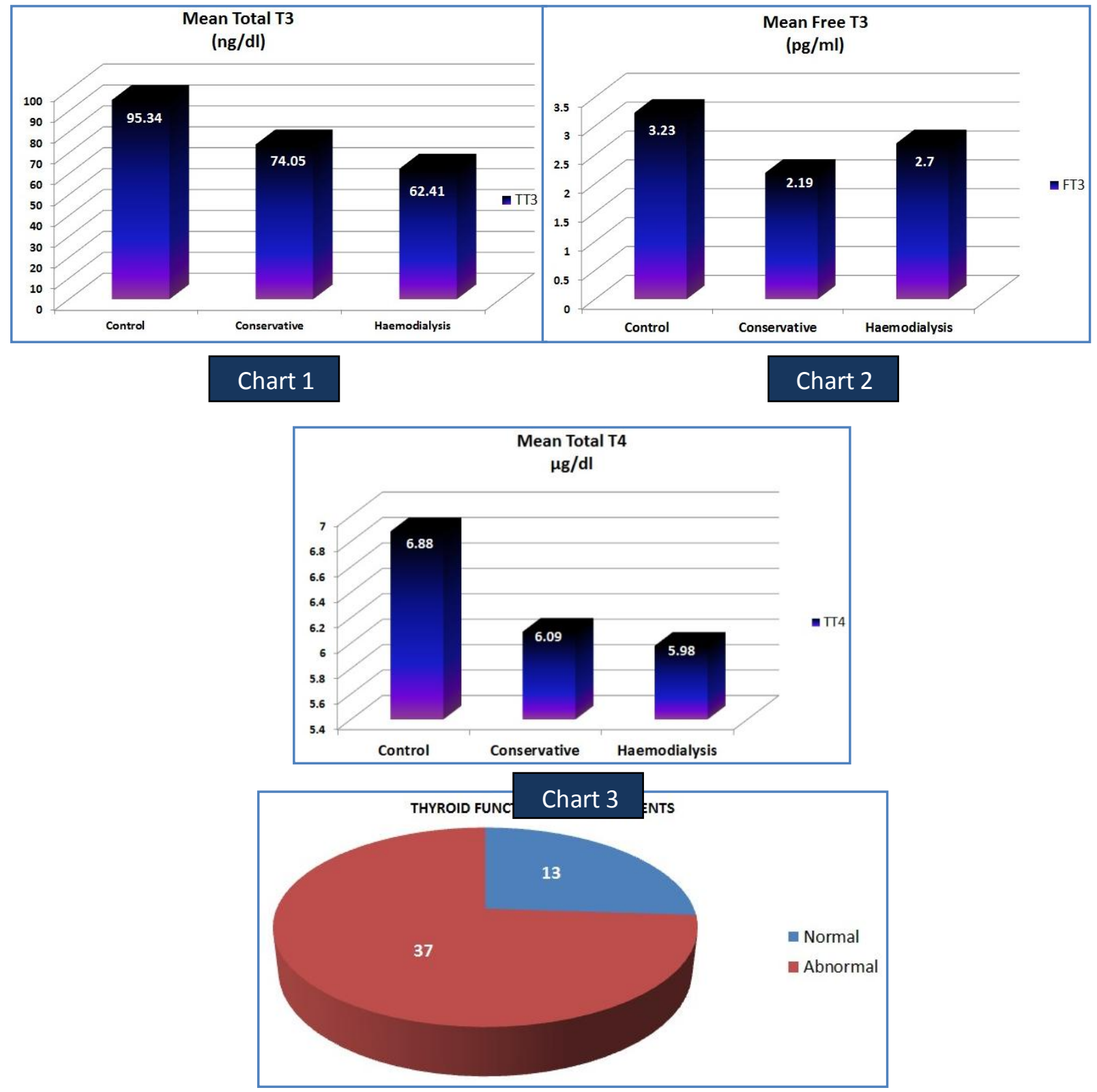

Pie 1 


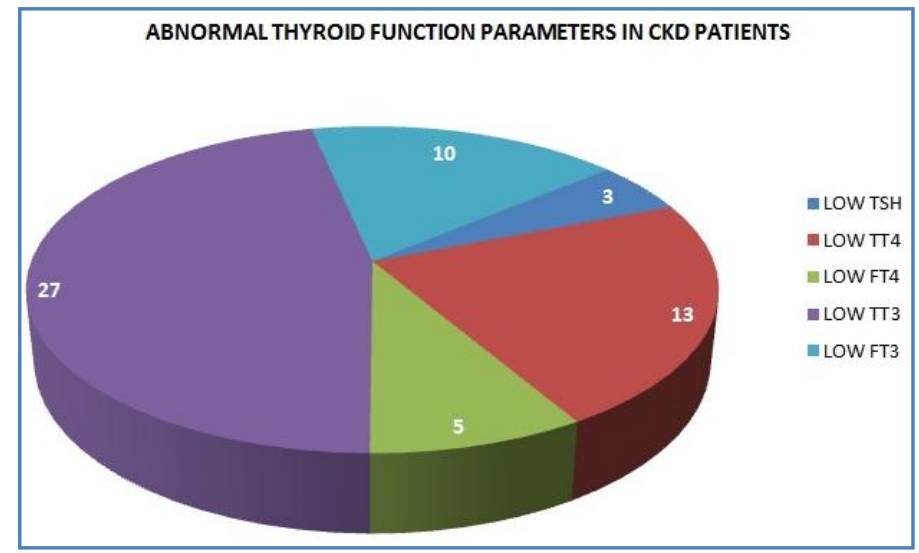

Pie 2

\section{AUTHORS:}

1. Jigar Haria

2. Manish Lunia

\section{PARTICULARS OF CONTRIBUTORS:}

1. Assistant Professor, Department of Medicine, Teerthanker Mahaveer Medical College \& Research Centre.

2. Senior Resident, Department of Gastroenterology, GB Pant Hospital, New Delhi.

\section{NAME ADDRESS EMAIL ID OF THE} CORRESPONDING AUTHOR:

Dr. Jigar Haria,

E-304, Faculty Block, TMU Cam pus, Delhi Road, Moradabad, Uttar Pradesh - 244001.

Email -dr.jigar.haria@gmail.com

Date of Submission: 07/10/2013.

Date of Peer Review: 08/10/2013.

Date of Acceptance: 21/10/2013.

Date of Publishing: 23/10/2013 